Int. J. Dev. Biol. 53: 1569-1579 (2009)

doi: $10.1387 / \mathrm{ijdb} .072351 \mathrm{jr}$

\title{
Frontiers in fluorescence microscopy
}

\author{
JOSÉ RINO*, JOSÉ BRAGA, RICARDO HENRIQUES and MARIA CARMO-FONSECA \\ Instituto de Medicina Molecular, Faculdade de Medicina, Universidade de Lisboa, Lisboa, Portugal
}

\begin{abstract}
How we see organisms and cells depends on the tools at our disposal. For over 150 years, biologists were forced to rely on fixed, dehydrated and stained specimens in order to guess how the living cells could function. It all changed abruptly during the last two decades when the rapid development of novel imaging techniques revolutionized the way scientists look at the structures of life alive.
\end{abstract}

KEY WORDS: fluorescence, photobleaching, photoactivation, FRET, FLIM

\section{A brief history of light microscopy}

More than 300 years ago, Antony van Leeuwenhoek observed for the first time bacteria and other unicellular organisms using simple microscopes that he himself designed and constructed. Leeuwenhoek's skills enabled him to build single-lens microscopes that magnified over 200 times, with clearer and brighter images than any of the existing compound microscopes could achieve. Although combining multiple lenses could in theory yield higher magnification, the early compound microscopes invented near the end of the $16^{\text {th }}$ century were limited by defects in the manufacturing of lenses, which greatly distorted the images. During the $19^{\text {th }}$ century the compound microscope finally evolved to become a reliable instrument allowing biologists to make the seminal discoveries that led to the formulation of the cell theory by Schleiden and Schwann in 1838.

The ultimate limit of all microscopes is resolution, or the capacity to clearly distinguish two separate point objects. Because of the wave nature of light, a single point object seen through a microscope appears as a blurred disc (the so-called Airy pattern, Fig. 1), and the discs produced by two point objects close together may overlap into a single merged image (Fig. 1C). Ernst Abbe was the first to demonstrate, in 1873, how the diffraction of light by both the specimen and the lenses affect image resolution. Theoretically, said Abbe, objects less than 200 $\mathrm{nm}$ apart cannot be resolved using visible light. This limit of resolution was nearly achieved by microscope makers at the end of the $19^{\text {th }}$ century.

The concept of resolution relates to the level of structural detail that can be seen when a sample is imaged. In a wide-field microscope, resolution is affected by light scattering: because the whole sample is illuminated, more than $90 \%$ of the light collected is out-of-focus. This greatly reduces image detail. "An ideal microscope would examine each point in the specimen and measure the amount of light scattered or absorbed by that point" noted Marvin Minsky, the inventor of the confocal microscope (Minsky, 1988). Minsky's invention in 1953 was far sighted and remained largely unnoticed until the development of lasers and the widespread use of fluorescent biological markers turned the confocal microscope into one of the most exciting instruments available to biologists toward the end of the 1980s.

The key feature of confocal microscopy is its ability to produce images of specimens at different depths with excellent contrast. Confocal laser scanning microscopes (CLSMs) are capable of slicing optical sections from thin biological samples, allowing them to be rendered in $3 D$ reconstruction images. Moreover, because most light coming from regions above or bellow the focal plane is blocked, out-of-focus light is not added to the image. This greatly improves depth discrimination and contrast (Stelzer, 1995). Additionally, the design of CLSMs provides a theoretical improvement of approximately $30 \%$ in resolution. However, this does not hold in practice for the observation of biological samples due to noise, pixelation and image aberrations of the system (Hell et al., 1993, Hell and Stelzer, 1995). Indeed, for the current generation of confocal microscopes the limit of resolution has been reached at around $200 \mathrm{~nm}$ in the lateral $(x, y)$ direction and $600 \mathrm{~nm}$ in the axial $(z)$ direction. Axial resolution can be increased with $4 \mathrm{Pi}$ confocal microscopes, which use two lenses instead of one, placed on both sides of the sample. This two-lens system was called $4 \mathrm{Pi}$ in reference to $4 \pi \mathrm{r}^{2}$ (the surface of a sphere) and the attempt to visualize a sample from all angles (Hell and Stelzer,

Abbreviations used in this paper: CLSM, confocal laser scanning microscope; FRAP, fluorescence recovery after photobleaching; FRET, Förster resonance energy transfer; GFP, green fluorescent protein.

\footnotetext{
*Address correspondence to: José Rino. Instituto de Medicina Molecular, Faculdade de Medicina, Av. Prof. Egas Moniz, 1649-028 Lisboa, Portugal. Fax: +351-21-799-9412. e-mail: joserino@fm.ul.pt
} 
1992b). Much like astronomers, microscopists then used the interference between two wave fronts originating from both objectives to yield more image information (Gustafsson et al., 1999, Hell and Stelzer, 1992a).

A drawback to the traditional CLSM is speed of image acquisition. Because the excitation laser source is scanned across the specimen in a point-by-point raster pattern, just one to three high resolution images can be captured per second. This will not be enough to image processes that occur in fractions of a second. This disadvantage is overcome with the spinning-disk (also called Nipkow-disk) confocal microscope that uses disks containing multiple pinholes to simultaneously illuminate and collect light from several points of the specimen. Imaging rates of up to 30 frames per second are obtained by rotating the disks at high speed. The main caveat of this approach however, is the highly inefficient excitation of the sample, as the vast majority of excitation light available is rejected by the pinholes (Nakano, 2002). Additional disadvantages include worse axial resolution, lesser homogeneity of field of illumination and less flexibility to changes in objectives and experimental settings (Wang et al., 2005).

Another drawback of CLSMs is their inability to image large, thick living specimens. This is because large specimens absorb and scatter a considerable amount of light. The advent of MultiPhoton Microscopy (MPM), introduced in 1990 by the work of W. Denk, J. Strickler and W. Webb (Denk et al., 1990) was the breakthrough in optical microscopy that allowed to fulfill the challenging task of imaging living organs such as brain and liver. MPM relies on the quasi-simultaneous absorption of two or more photons by a molecule (i.e., the fluorescent marker). The multiphoton absorption process, first predicted in 1930 by Maria Göppert-Mayer, needs a very high density of photons from a pulsed light source. Two-photon fluorescence microscopy (2PFM) is currently the most common multi-photon fluorescence application in biology. Commercially available instruments use a laser operating in the range of $720-920 \mathrm{~nm}$. While photodamage is lower and penetration depth is higher, the resolution obtained with these long illumination wavelengths is necessarily less good than in the traditional confocal microscope.

An alternative to visualize large living specimens with higher resolution was more recently developed. The so-called selective plane illumination microscopy (SPIM) is a system that combines two-dimensional illumination with orthogonal camera-based detection. SPIM generates multidimensional images of samples up to a few millimeters in size with high-resolution and minimal photodamage (Huisken et al., 2004, Verveer et al., 2007).

Of all the numerous developments introduced in light microscopy over the past century, the most spectacular breakthrough was the demonstration that the resolution of images obtained with a fluorescence microscope is no longer limited by the wavelength of the light, as postulated by Abbe. This ingenious trick makes use of the nonlinear excitation properties of fluorophores. The principle of stimulated emission depletion (STED) microscopy is to make the fluorescent spot smaller by quenching the excited molecules at the rim. Two synchronized trains of laser pulses are employed for this purpose. A visible pulse excites the fluorophores in the focus and a subsequent red-shifted pulse performs the quenching. By using enough photons, the quenching process is saturated and this "helps to squeeze the spot down to a very small scale, in principle infinitely" says Stephen Hell, the inventor of STED (Dyba and Hell, 2002, Hell and Wichman, 1994, Klar et al., 2000). This novel microscopy, which has recently become commercially available, has already proved to be applicable to live specimens, resolving the fate of individual synaptic vesicles (approximately $40 \mathrm{~nm}$ in diameter) after neurotransmitter release (Willig et al., 2006).

\section{Fluorescence and fluorophores}

Fluorescence is the process by which molecules become excited and emit light with defined wavelengths as a consequence of having absorbed photons with shorter wavelengths (Stokes, 1852). The difference between the exciting and emitted wavelengths, known as the Stokes shift, depends on the outmost electron orbitals of the fluorescent molecule, or fluorophore. Fluorescent compounds at room temperature are normally in the lowest vibrational levels of the ground state $\left(S_{0}\right.$ where $S$ stands for singlet state). When a photon is absorbed, all its energy is transferred to the fluorescent molecule. However, for fluorescence to occur the minimum energy of an incoming photon must correspond to the energy difference between the lowest energy level of the first excited state $\left(S_{j}\right)$ and $S_{o}$ (Fig. 2A). Photons with higher energies induce transitions into higher vibrational and rotational levels or to higher energy states $\left(\mathcal{S}_{2}, \mathcal{S}_{3}, \ldots\right)$. The energy ( $E$ ) of a photon is $E=h \times c / \lambda$ (where $h$ is Plank's constant, $c$ is the speed of light and $\lambda$ is the photon's wavelength in vacuum), and each fluorophore can be excited by a range of wavelengths that define its absorption spectrum.

Excited states are usually very unstable and the molecule
Fig. 1. The Airy pattern.

(A) A point source emits light waves in all directions. A fraction of these is captured by the objective lens, at a cone with a half-angle $\theta$. The light waves are then diffracted by the lens but instead of being focused into an infinitely small point, they converge and interfere with each other at the
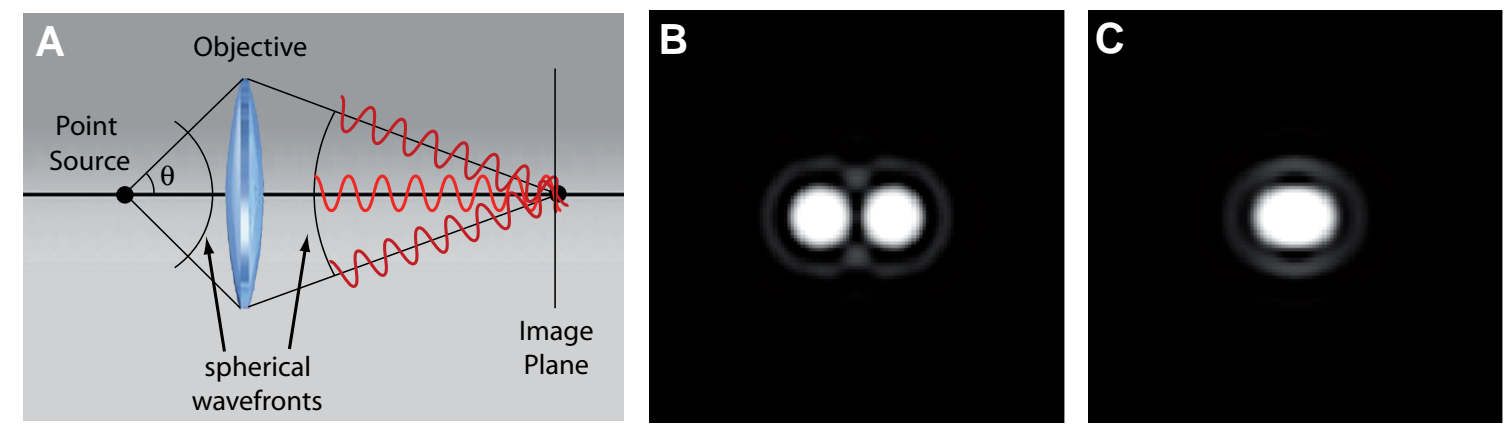

image plane, producing a diffraction Airy pattern. (B) Airy patterns for two point objects which are sufficiently separated in order to be clearly resolved. (C) Two point objects are not resolved if their separation is not sufficient to produce a contrast between them. 

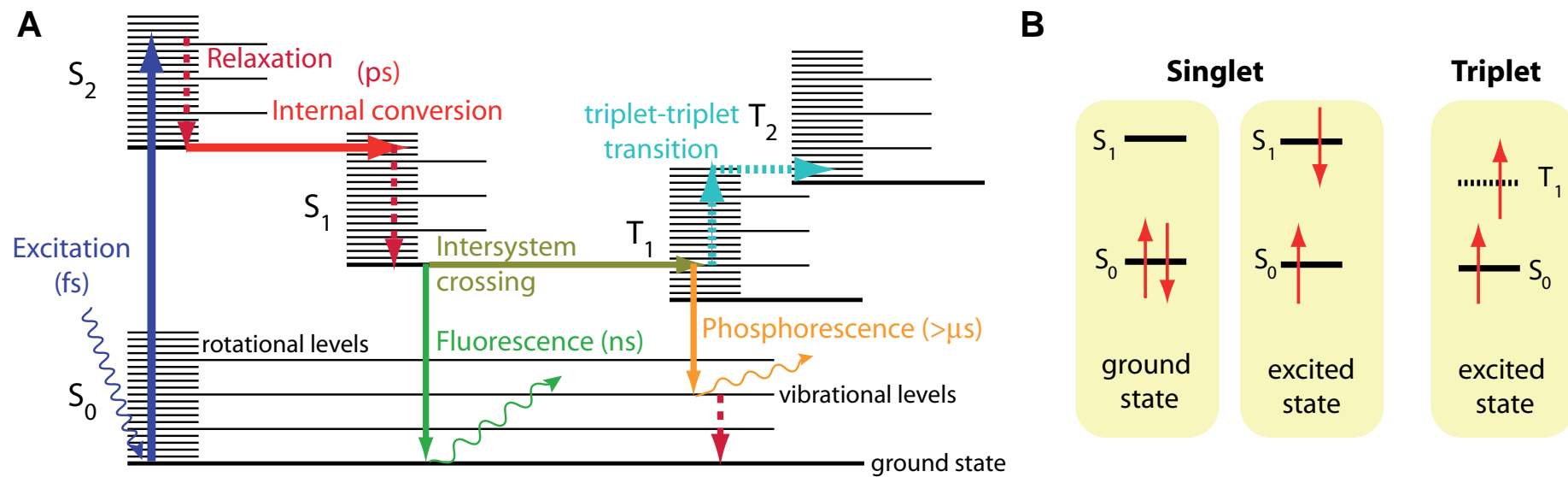

Fig. 2. Excitation and emission of light by a fluorophore. (A) The energy states of a fluorophore molecule are represented in this Jablonski diagram together with the times that the various steps in fluorescence excitation, emission and phosphorescence take. The electronic levels are indicated by thick black horizontal lines, whereas the vibration and rotational levels are represented by thinner lines. When a photon with the appropriate wavelength is absorbed by the molecule, it causes a transition to a high vibrational level of the excited electronic state $S_{2}$ (dark blue arrows). The molecule then undergoes rotational and vibrational relaxations (dotted dark red arrows) and internal conversion (red arrow) before it reaches the lowest energy level of $S_{1}$. Transition to the ground state usually occurs via emission of a photon, by fluorescence (green arrows). Alternatively the molecule might undergo intersystem crossing (brown arrow) and arrive at a triplet state, where it may cause phosphorescence emission (orange arrows) or triplet-triplet transitions (light blue arrows) that further delay the emission of light or prevent it altogether. (B) Electrons are usually paired with anti-parallel spins in a singlet state. If an electron is excited, the system maintains their anti-parallel configuration; however, there is a low probability that an excited electron reverses its spin. In this situation the system is in a triplet state $T_{1}$.

will tend to return to its low-energy ground state. Rotation, vibrational relaxation and "internal conversion" will bring the excited molecule to the lowest energy level of $S 1$ in picoseconds, without emission of radiation. Only when the molecule returns to any of the vibrational levels of SOdoes fluorescence occur, with emission of a photon with energy equivalent to this transition. The wavelength range of an emission spectrum thus reflects the different transitions from the lowest level of $S 1$ to the different rotation and vibrational levels of the ground state.

The process just described involves the absorption of one single photon at a time. However, with very high photon densities it is possible that a molecule absorbs two (or more) photons almost instantaneously. In this case, a transition to an excited state occurs if the sum of energies of the photons is at least equal to the energy gap between $S_{1}$ and $S_{0}$. This implies that multi-photon fluorescence can be obtained using less energetic, longer wavelengths for excitation.

The time it takes before an excited fluorophore undergoes the transition from the lowest level of $S 1$ to the ground state is called the excited state lifetime. The lifetime of a fluorophore, which is usually in the nanosecond range, can be reduced if another nearby molecule absorbs the energy in a non-radiative manner, preventing the fluorophore from emitting a photon (quenching). These lifetime reductions due to intermolecular interactions can be measured by a technique called Fluorescence Lifetime Imaging Microscopy (FLIM). If the nearby interacting molecule is itself a fluorophore, the absorbed energy can in turn lead to its excitation and subsequent fluorescence. This phenomenon, known as Fluorescence Resonance Energy Transfer (FRET) can be probed by a variety of techniques, providing information on intramolecular distances far below the resolution of an optical microscope.

During the process of relaxation, the molecule may make a transition to unlikely states called triplet states. In these states, the excited electron inverts its spin state (Fig. 2B) and thus the overall magnetic moment of a molecule will change. These excited states usually last for a long time because further relaxation can only occur if the molecule undergoes another unlikely spin-inverting transition. Triplet states can sometimes reach the ground state by emitting a photon, in a process called phosphorescence. Alternatively, they may undergo triplet-triplet transitions into higher triplet states if another photon is absorbed, further delaying any light emission by the molecule.

The intrinsic brightness of a fluorophore is determined by its photostability, quantum yield and molar extinction coefficient (Shaner et al., 2005). The quantum yield $(\Phi)$ is a measure of the fluorophore's total light emission over the entire spectral range. It is defined as the ratio between the numbers of emitted and total absorbed photons and has a value between 0 and 1 . The molar extinction coefficient $(\mu)$, or molar absorption coefficient, corresponds to the absorbance of light per unit path length and per unit of concentration of a given fluorophore. Its value, calculated as $\mu=\mathrm{A} / \mathrm{C}$ (where $A$ is the absorbance and $C$ the fluorophore's concentration) reflects the probability of a photon to be absorbed by the fluorophore. The higher the value of quantum yield and molar extinction coefficient, the brighter is the fluorophore. Stability relates to the fact that fluorophores can only undergo a limited number of cycles of absorption and emission. All fluorophores will eventually photobleach by mechanisms that are not completely elucidated but most probably involve triplet states. As triplet states are long-lived, the excited molecules have more time to interact with other molecules such as oxygen. Molecular oxygen is a ground state triplet which, by interaction with a molecule in a triplet state, may make a transition to a highly reactive excited singlet state. This excited molecule in turn can react with either another fluorophore (chang- 
ing irreversibly its structure) or other organic molecules causing phototoxicity (Lichtman and Conchello, 2005).

\section{The GFP revolution}

The discovery and development of the Green Fluorescent Protein (GFP) and related fluorescent proteins (FPs) originated an extraordinary revolution in biological research, which was recently acknowledged with the attribution of the Nobel Prize in Chemistry 2008 to Osamu Shimomura, Martin Chalfie and Roger Y. Tsien. With these genetically encoded markers it became possible to fluorescently tag almost any protein with minimal invasiveness (Heim et al., 1995). However, not all fluorescent chimeras are successful. FP tagging can sometimes alter the endogenous protein folding, rendering it non-functional. Therefore, it is crucial to perform careful and detailed biological controls to ensure the functionality of the fusion protein.

The GFP from the jellyfish Aequorea victoria (avGFP) was the first fluorescent protein to be cloned (Tsien, 1998). The protein is a $27 \mathrm{kDa}$ monomer with a cylindrical shape composed of a 11stranded $\beta$-can, $42 \AA$ long and $24 \AA$ in diameter, with both ends closed by short helical segments (Fig. 3A). The chromophore ( $p$ hydroxybenzylideneimidazolidinone) is almost perfectly buried in a $\alpha$-helix at the center of the cylinder. This configuration is thought to be responsible for the high stability of GFP. Indeed, the protein is highly resistant to denaturation, proteolysis and quenching by molecular oxygen or $\mathrm{pH}$ changes (Ormo et al., 1996). The mature chromophore is formed autocatalytically by a series of intramolecular reactions involving amino acids 65-67 (Ser-Tyr-Gly) and the only exogenous reagent needed is oxygen (Prendergast, 1999, Reid and Flynn, 1997).

Despite its great potential, the wild type avGFP was not an ideal fluorophore. The excitation spectrum had two peaks (at 396 and $475 \mathrm{~nm})$ and the molar extinction coefficient was low $(22,000$ $\mathrm{M}^{-1} \mathrm{~cm}^{-1}$, compared to fluorescein's $80,000 \mathrm{M}^{-1} \mathrm{~cm}^{-1}$ ). Moreover, the protein took a relatively long time to mature in cells and had a tendency to dimerize at high concentrations (Cubitt et al., 1995). Serious mutagenesis efforts followed by rational fluorescent protein design led to the progressive development of improved versions of the protein, such as the enhanced GFP (EGFP), enhanced blue fluorescent protein (EBFP), enhanced cyan fluorescent protein (ECFP) and enhanced yellow fluorescent protein (EYFP) (Lippincott-Schwartz and Patterson, 2003, Shaner et al., 2005, Tsien, 1998).

A variety of additional mutations aiming to reduce dimerization and improving chromophore maturation have culminated in the development of vastly improved fluorophores. These include monomeric versions of the blue, cyan, green and yellow versions of GFP (mBFP, mCFP, mGFP, mCitrine and mVenus (Zhang et al., 2002)) and also mCerulean (excitation: $433 \mathrm{~nm}$; emission: 475 $\mathrm{nm}$ ) (Rizzo et al., 2004) and T-Sapphire (excitation: $399 \mathrm{~nm}$; emission: $511 \mathrm{~nm}$ ) (Zapata-Hommer and Griesbeck, 2003), which are specially suited for FRET applications.

On the other side of the spectrum, a red fluorescent protein from the coral Discosoma, called DsRed (Matz et al., 1999), was also mutated to generate a monomeric red fluorescent protein (mRFP1) (Campbell et al., 2002). More recent mRFP1 mutagenesis improved brightness and photostability leading to a plethora of new monomeric spectral mutants (Shaner et al., 2004), which

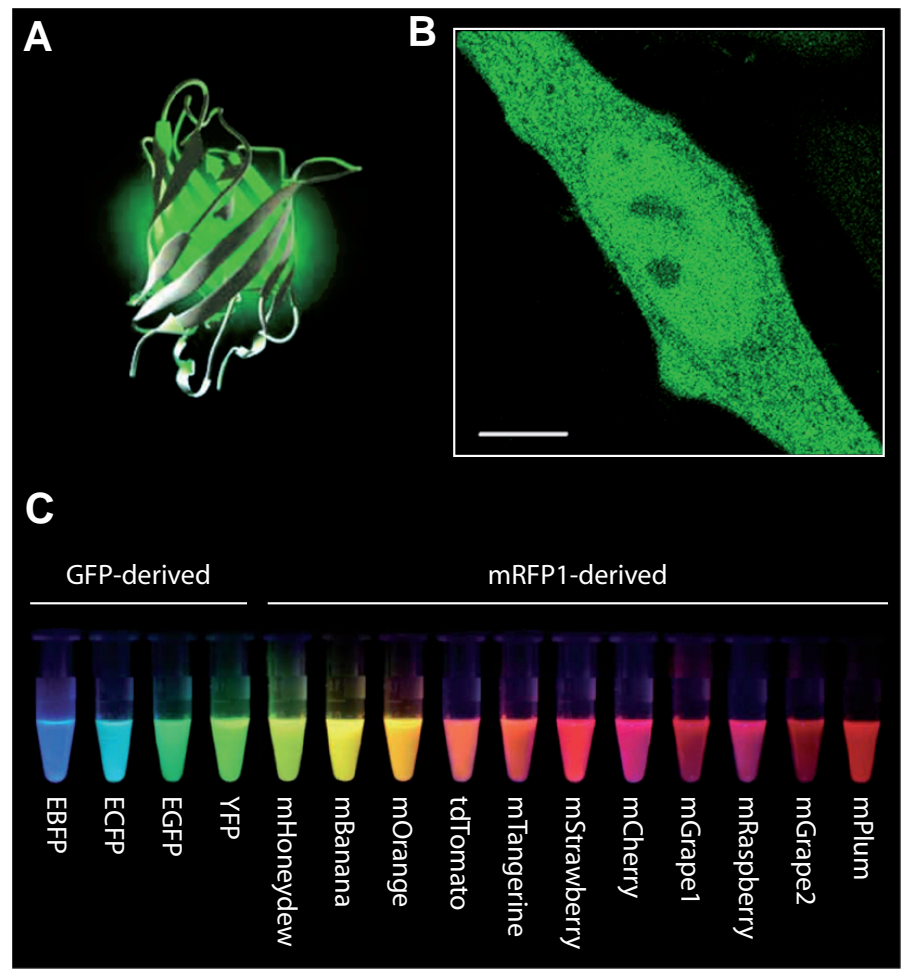

Fig. 3. The Green Fluorescent Protein and variants. (A) GFP folds into a $\beta$-can structure with the chromophore buried inside the cylinder-shaped molecule, which has a diameter of about $25 \AA$ and a length of $40 \AA$. (B) Enhanced GFP (EGFP) expressed in a transfected human cell, visualized by confocal microscopy. Bar: $5 \mu \mathrm{m}$. (C) Engineered fluorescent proteins, derived from GFP and the monomeric Red Fluorescent Protein (mRFP1), covering the full visible emission spectrum. Protein samples are shown in purified forms inside Eppendorf tubes. Adapted from (Tsien, 2005).

range from the greenish mHoneydew to the far red mPlum and include the highly photostable and fast maturing mCherry (Fig. 3C).

Further innovation was introduced by the development of photoactivatable and photoswitchable fluorescent proteins (Lukyanov et al., 2005). These fluorophores are capable of pronounced changes in their spectral properties once irradiated with light of a specific wavelength and intensity. Photoactivatable GFP (PA-GFP) and photoswitchable CFP (PS-CFP) were both developed from avGFP, taking advantage of the wild type protein double excitation peaks. PA-GFP is the result of a single point mutation $\left(\mathrm{Thr}_{203}\right.$ His) in avGFP (Patterson and LippincottSchwartz, 2002). The non-photoactivated form of the protein is characterized by $400 \mathrm{~nm}$ excitation and $515 \mathrm{~nm}$ emission peaks, with almost no fluorescence emission when excited at $480-510$ $\mathrm{nm}$. Irreversible photoactivation by intense UV light ( $400 \mathrm{~nm})$ results in a 100-fold increase of green fluorescence (excitation: $504 \mathrm{~nm}$; emission: $517 \mathrm{~nm}$ ). Non-photoactivated PS-CFP shows cyan fluorescence instead, with an emission peak at $468 \mathrm{~nm}$ (Chudakov et al., 2004). Irreversible photoconversion with intense UV light then provokes a 300-fold increase in green fluorescence (excitation peak: 490nm; emission peak: $511 \mathrm{~nm}$ ) accompanied with a 5-fold reduction in cyan fluorescence. Photoactivatable red fluorescent proteins have also been devel- 
oped, such as the monomeric PA-mRFP (Verkhusha and Sorkin, $2005)$, which requires intense $380 \mathrm{~nm}$ activation to exhibit a 70fold increase in red fluorescence (excitation: $578 \mathrm{~nm}$; emission: $605 \mathrm{~nm}$ ). Other photoconvertible proteins able to convert irreversibly from green to red upon UV illumination include Kaede (Ando etal., 2002), mEosFP and KikGR (Lukyanov etal., 2005). Reversible conversion, on the other hand, can be achieved with the tetrameric kindling fluorescent protein (KFP1), converted by 488 nm illumination (Chudakov et al., 2003) or Dronpa, (Ando et al, 2004) and its fast-switchable variant rsFastLime (Stiel, Trowitzsch et al., 2007) which can both be activated by $405 \mathrm{~nm}$ UV light and deactivated with $488 \mathrm{~nm}$ illumination. The recent development of Dendra (Gurskaya et al., 2006) resulted in the first monomeric protein capable of green $(488 \mathrm{~nm})$ photoactivation. Both Dendra and PS-CFP have recently been optimized to generate Dendra2 and PS-CFP2 respectively, both of them monomeric derivatives which display enhanced brightness and accelerated maturation rates at $37^{\circ} \mathrm{C}$ (Chudakov et al., 2007).

\section{Quantum dots}

To overcome the limitations imposed by the photostability of standard dyes, alternatives have been sought. Quantum dots (QDs) are small nanocrystals, 2-8 $\mathrm{nm}$ in diameter, which have very interesting optical properties (Gao et al., 2005). Excitation and absorption spectra are dependent on the size and composition of QDs. Usually, excitation spectrum is broad and the emission spectrum narrow, thus QDs with different emission spectra can be excited with only one wavelength, which makes them specially suited for multiple color applications. Due to a high extinction coefficient QDs are much brighter than most organic fluorophores, though their main advantage is that they are much more resistant to bleaching. Another advantage is that they are non-toxic to cells. To date, QDs in cell biology are most often used as labels for immunofluorescence (Michalet et al., 2005). However, QDs have already been applied in vivo to track singlemolecule movement inside cells (Dahan etal., 2003) and to image lymph nodes and tumours at the whole-organism level (Gao et al., 2005). Blinking of QDs, which can occur in a wide range of times ( $100 \mu \mathrm{s}-100 \mathrm{~s})$, is one the major disadvantages of these probes because it restricts quantitative analysis (Arya et al., 2005).

\section{Photobleaching methods}

The advent of live cell imaging by time-lapse microscopy using fluorescent proteins as molecular tags triggered a large number of studies on the localization and dynamics of cells and subcellular structures. However, in order to obtain information on the dynamics of the components of sub-cellular structures at the molecular level, new methods had to be developed.

Although photobleaching of fluorophores is usually undesirable in most fluorescence microscopy applications, more than thirty years ago it was devised purposefully as a tool to study molecular dynamics (Cone, 1972, Edidin etal., 1976, Peters etal., 1974, Poo and Cone, 1973). This technique was to become known as fluorescence recovery after photobleaching (FRAP).

FRAP is based on the local perturbation of the fluorescence steady-state by inducing irreversible photobleaching with an intense light source at a selected region of interest (Fig. 4). Then, due to the motion of unbleached fluorophores from regions not affected by bleaching, fluorescence relaxes to a new steadystate. The rate by which this relaxation occurs is related with the overall mobility of the fluorescently-tagged molecule: a higher mobility implies a faster recovery of fluorescence inside the bleached region (Fig. 4D, E). Monitoring of recovery should be performed with minimal light intensity to avoid significant and global unspecific bleaching of the sample. In the case that all fluorescent molecules are mobile (Fig. 4A, D), the fluorescence intensity will reach a plateau that will correspond to the initial prebleach fluorescence value, provided that the bleach region is small (typically with a diameter of $\sim 1 \mu \mathrm{m}$; Braga et al., 2004). If fluorescence recovery does not return to the initial pre-bleach value (Fig. 4E) then either there is an immobilized sub-population of fluorescent molecules in the bleach region (Fig. 4B) or a significant amount of the total number of fluorescent molecules was lost during bleaching (Fig. 4C).

FRAP is easily implemented in most standard CLSMs, which largely contributed to the increased availability and popularity of

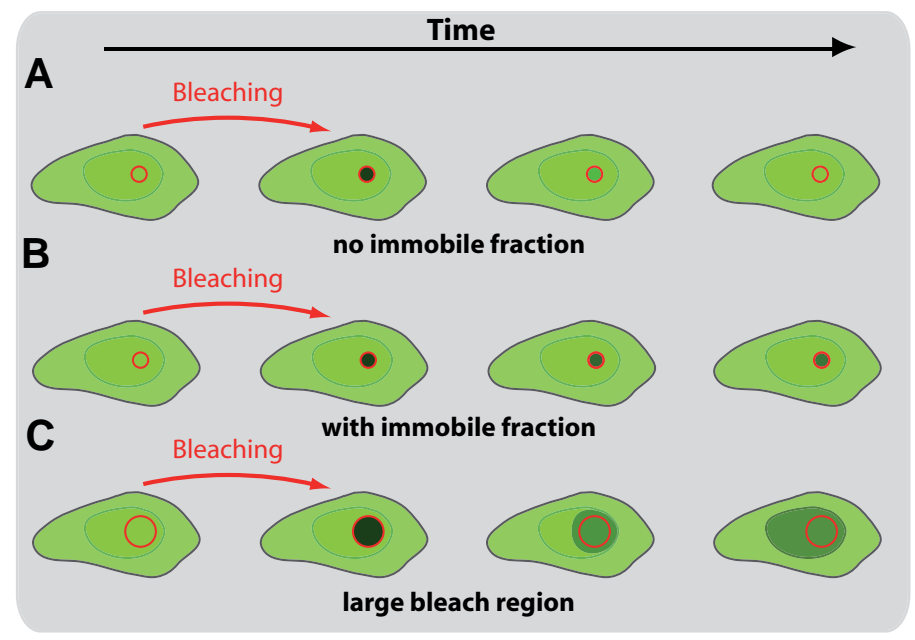

D

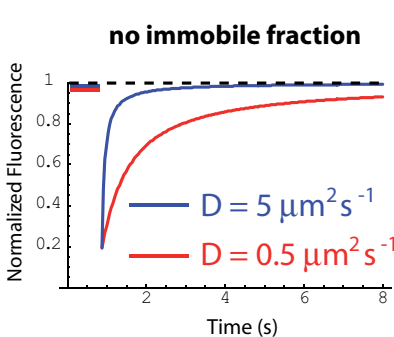

$\mathbf{E}$

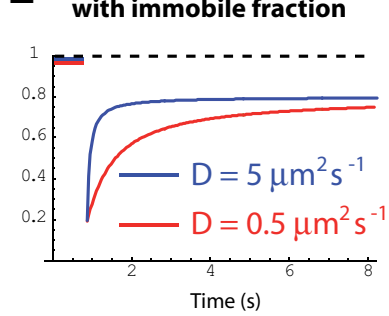

Fig. 4. Fluorescence Recovery After Photobleaching (FRAP). (A) In FRAP, a cell is imaged before and after bleaching a small spot. As all the molecules are mobile, fluorescence in the bleach region eventually recovers to its initial state. (B) If some molecules are stalled in the bleach region, final fluorescence will be lower than initial fluorescence. (C) Due to the finite size of the cell (or the nucleus, in the case depicted) bleaching a large region will deplete a significant proportion of the fluorescent pool, thus leading to incomplete recovery. (D) Simulated FRAP recovery curves show that species with different rates of movement will yield different recovery curves. Fluorescence values are normalized for the initial intensity. (E) Same as in (D), but with $25 \%$ of the molecules immobilized in the bleached region. 


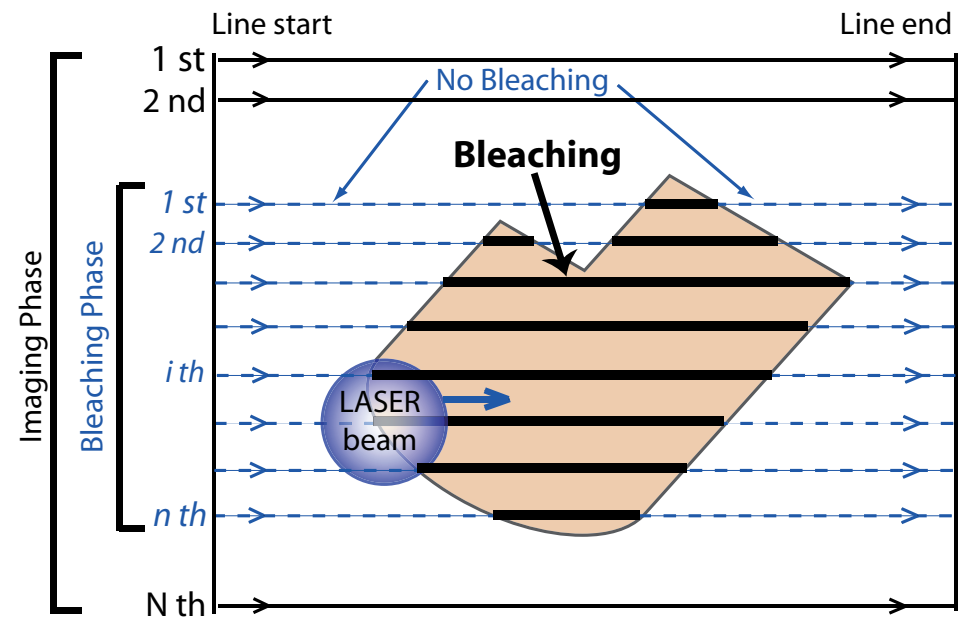

Fig. 5. Schematics of bleaching with a Confocal Laser Scanning Microscope (CLSM). The software of a CLSM allows for arbitrary 2D shapes to be drawn in the sample. A laser beam scans the region (comprising a total of $n$ lines, numbered in italic), for a certain number of iterations. The laser beam has a certain width (depicted as the blue transparent circle). Laser intensity is high inside the user defined region (thick lines) and nearly zero outside (dashed blue lines). After bleaching, the entire region is imaged. For imaging, the monitoring beam scans the whole image with constant illumination intensity. The resulting image contains the bleached region of interest (ROI) and consists of $N$ lines (numbered in normal lettering), with $N>n$. (adapted from Braga et al., 2004)

the technique (Fig. 5). FRAP has been extensively used in a wide variety of biological applications and the information extracted from these experiments range from purely qualitative to sophisticated quantification of diffusion and binding parameters. The technique can be used to evaluate if a protein is a stable component of a cellular structure or otherwise is in constant exchange between different pools (Boisvert et al., 2001, Desterro et al., 2003, McNally et al., 2000, Tavanez et al., 2005, Trinkle-Mulcahy et al., 2001). A direct comparison of recovery curves from the same molecule under different experimental conditions may already show biologically relevant differences in mobility.

Extracting quantitative parameters from FRAP recovery curves is not a trivial task. Simple approaches consist in calculating the time it takes to reach a defined percentage of recovery (Cheutin et al., 2003, Harrer et al., 2004, Sunn et al., 2005), measure the percentage of recovery observed after a fixed time period (McDonald et al., 2006), and fit recoveries to either one exponential (Belgareh et al., 2001, Lam et al., 2002, Lang et al., 1986) or a sum of exponentials (Handwerger et al., 2003, Kimura and Cook, 2001). However, care must be taken as diffusion-like recoveries are apparently properly fitted with 2 or more exponentials, but this type of fitting gives incorrect information about the underlying process (Sprague et al., 2006, Sprague et al., 2004).

More accurate, yet much more laborious methods involve solving the diffusion equation. After the pioneering work developed thirty years ago by Axelrod and co-workers (Axelrod et al., 1976), several mathematical approaches have been devised to extract mobility parameters (Blonk etal., 1993, Braeckmans etal., 2003, Braeckmans etal., 2006, Braga et al., 2004, Kubitscheck et al., 1998) and binding parameters from biological FRAP data (Beaudouin et al., 2006, Braga et al., 2007, Carrero et al., 2003,
Sprague et al., 2006, Sprague et al., 2004). The choice of a method for analysis of FRAP data should be guided by the level of precision desired and the practicality of its implementation, However, and most importantly, the underlying assumptions of the models (such as negligible beach time, two-dimensional diffusion, very fast diffusion compared to binding) should be analyzed carefully in order to check the applicability of the method to the situation being studied.

Fluorescence loss in photobleaching (FLIP) consists on the repetitive photobleaching of a defined cellular region (Fig. 6). Fluorescence intensity is monitored over regions of interest distant from the bleached region (Cole et al., 1996). FLIP is mainly used to assess whether the tagged molecule shuttles between the bleached and imaged regions (Goodwin and Kenworthy, 2005, Lippincott-Schwartz et al., 2003, Lippincott-Schwartz et al., 2001).

Inverse FRAP (iFRAP, Fig. 6) consists in photobleaching an entire cell or sub-cellular structure with the exception of a region of interest. Fluorescence loss in the region of interest is subsequently monitored over time. This method yields information on the mobility rate and residence time of the tagged molecule in the region of interest (Dundr et al., 2002, Lippincott-Schwartz et al., 2003). However, because a considerable amount of time is required to bleach the whole cell, iFRAP can only be applicable to molecules with slow kinetics, such as nucleoporins at the nuclear pore complex (Rabut et al., 2004). Photoactivation (PA) or photoconversion methods circumvent this limitation (see bellow).

FRAP for immobilization measurement (FRAP-FIM, Fig. 6) specifically aims at quantifying the percentage of immobile molecules in a given region of the cell (Houtsmuller et al., 1999, Rademakers et al., 2003). In this method, spot bleaching is performed by a relatively long bleach pulse $(\sim 5 s)$ at low laser intensity, allowing for diffusion of molecules to occur during the bleach phase. Confocal images acquired before and after bleaching are used to calculate the fluorescence ratio before and after bleaching as a function of the distance to the bleached spot. Transiently immobilized molecules at the bleached region can be followed by recording post-bleach images at increasing time intervals. Plotting the average immobile fraction as a function of time allows to estimate the average binding time of the molecules at the region of interest (Houtsmuller and Vermeulen, 2001).

\section{Photoactivation and photoconversion}

Photoactivation or photoconversion of fluorophores at a specific region of interest allows for a selected population of tagged molecules to be rendered visible (Fig. 6). The dynamics of the selected pool of molecules can then be directly monitored over time (Chapman et al., 2005, Deryusheva and Gall, 2004). Thus, compared to photobleaching, the main advantage of these methods is that they allow the identification and tracking of a specific population of molecules. By photoactivation, an initially faint fluorophore is illuminated with specific wavelengths that cause an increase in its fluorescence. For example, after UV irradiation, the fluorescence of photoactivatable GFP (PA-GFP) increases by a factor of 100 (Patterson and Lippincott-Schwartz, 2002). By photoconversion, the absorption and emission spectra of a fluorophore change upon illumination with specific wavelengths. 

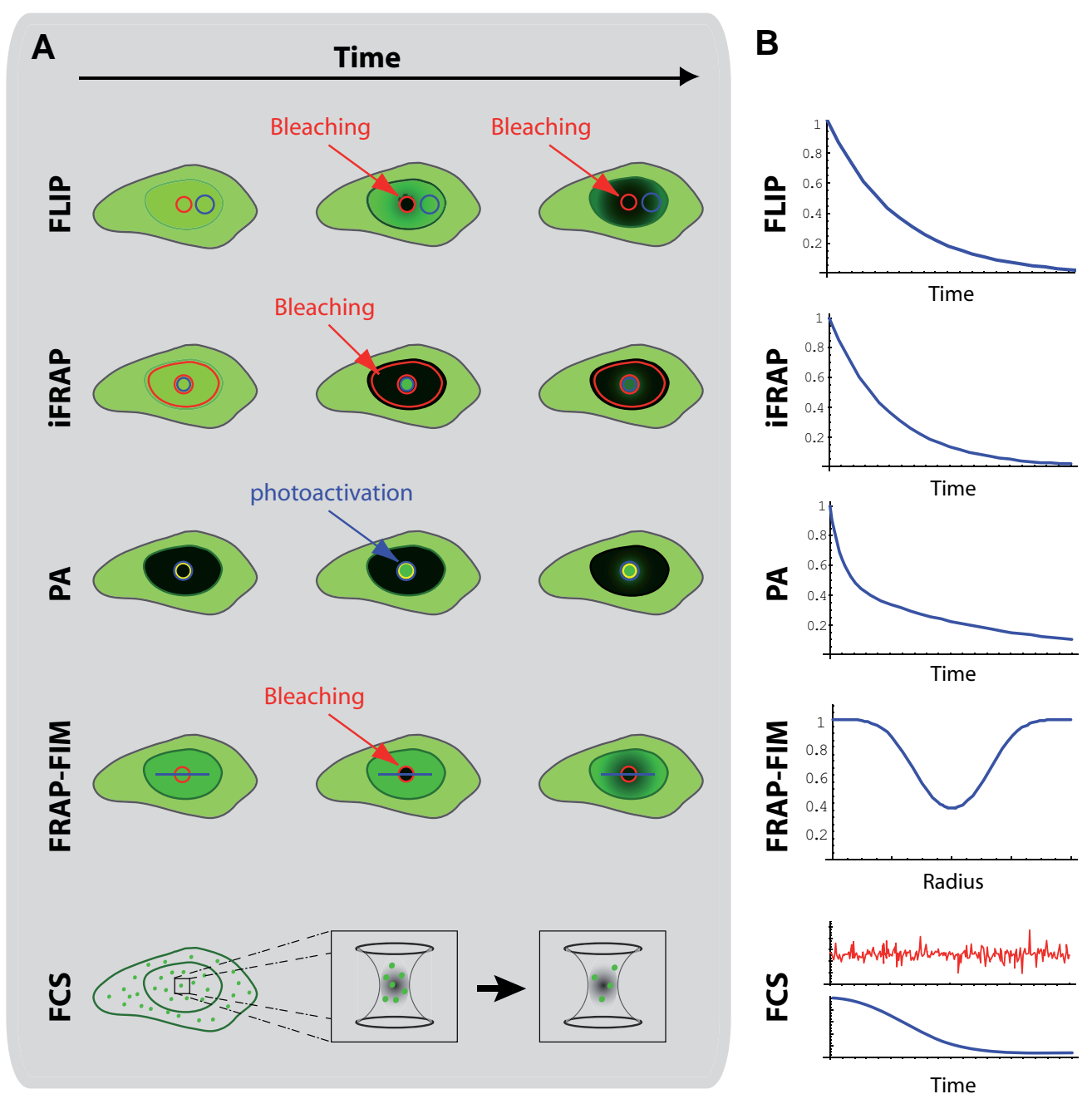

Fig. 6. FRAP variants and other methods for measuring molecular mobility. (A) Schematics of the Fluorescence Loss In Photobleaching (FLIP), inverse FRAP (iFRAP), photoactivation (PA), FRAP for immobilization measurement (FRAP-FIM) and fluorescence correlation spectroscopy (FCS) techniques. The regions delimited by the red line indicate bleaching regions, yellow circles photoactivation regions. Monitored regions are outlined by blue circles (FLIP, iFRAP and PA) or by a blue line (FRAP-FIM). In FCS, the monitored region is limited to a focal volume of less than one femtoliter (hourglass-shaped volumes). (B) Normalized fluorescence curves obtained from the different techniques are plotted over time (iFRAP and $P A)$ or over the bleach radius (FRAP-FIM). In FCS, the fluorescence fluctuation curves (red graph) are used to calculate the autocorrelation function (blue graph). See text for details.

Photoswitchable fluorophores that convert from green to red under UV illumination have already been used to study the dynamics of proteins inside cells (Ando et al., 2002, Deryusheva and Gall, 2004). However, care must be taken with choosing a photoactivatable/photoswitchable fluorescent protein, as only the most recently developed monomeric ones can be used for individual protein tagging. Non-monomeric proteins, such as tetrameric KFP1 should only be used to label whole cells or organelles (Lukyanov et al., 2005).

\section{Fluorescence correlation spectroscopy}

Contrasting with the previously described techniques that involve photobleaching or photoactivation of tagged molecules, in fluorescence correlation spectroscopy (FCS) the primary parameter of interest is not the intensity of fluorescence emission (Bacia and Schwille, 2003, Elson and Magde, 1974, Elson, 2004, Gosch and Rigler, 2005, Kim et al., 2005, Schwille, 2001). FCS consists in measuring, with high temporal resolution, fluorescence fluctuations in the diffraction-limited volume defined by a focused laser beam (Fig. 6). Unlike photobleaching or photoactivation microscopy, which uses micromolar to milimolar concentrations of fluorescent molecules, FCS typically uses femtoliter detection volumes and nanomolar concentrations of tagged molecules (Schwille et al., 1999). Within the observation volume only a few molecules are present. Because the molecules are moving in and out of that volume, the number of molecules detected is stochastically fluctuating around a mean value. Presumably the fluorescence measured at one particular instant is strongly correlated with the fluorescence measured shortly after but will possibly be weakly correlated with fluorescence at distant times. These correlations will vanish more rapidly in the case of a fast moving species. By computing the autocorrelations of the fluctuations it is possible to deduce the diffusion coefficient of the molecules (Bacia and Schwille, 2003). FCS further allows binding studies to be performed, by tagging two interacting molecules with different fluorophores (Bacia and Schwille, 2003).

\section{Förster resonance energy transfer (FRET)}

Protein-protein interactions are not directly discernible by light microscopy. The relative proximity of two proteins tagged with different fluorophores can only be determined by conventional fluorescence microscopy to the scale of roughly $\sim 200 \mathrm{~nm}$, the limit of optical resolution imposed by the diffraction barrier. However, protein-protein interactions require proximity distances within the range of $1-10 \mathrm{~nm}$ (Heim et al., 1995). This degree of resolution can only be achieved in light microscopy through the use of Förster resonance energy transfer (FRET) methods (Wallrabe and Periasamy, 2005, Wouters et al., 2001).

Förster resonance energy transfer, also called fluorescence 
resonance energy transfer, is a phenomenon that occurs when two different fluorophores (called donor and acceptor) with overlapping emission/absorption spectra are in close proximity to each other and in a suitable orientation (Selvin, 2000, Truong and Ikura, 2001, Voss et al., 2005). FRET involves the non-radiative transfer of energy (no photons are emitted) from an excited state in the donor fluorophore to the nearby acceptor.

The energy transfer efficiency $E$ is related to the distance $r$ between the donor and acceptor fluorophores by $E=1 /\left[1+\left(r / R_{0}\right)^{6}\right]$, where $R_{0}$ is the Förster radius, the distance at which the efficiency of energy transfer is $50 \%$ of maximum. The Förster radius depends on the extent of overlap between the donor emission and the acceptor excitation spectra, the absorption coefficient of the acceptor, the quantum yield of the donor and the relative orientation of the donor and acceptor (the donor and acceptor transition dipoles must be aligned relative to each other).

The value of $R_{0}$ effectively defines the resolution of FRET, which is typically $<10-100 \AA$. Because FRET falls off as the sixth power of the distance between the donor and acceptor, when these molecules are separated by distances greater than $2 R_{0}$ no FRET occurs. The phenomenon of FRET can thus be applied in fluorescence microscopy to distinguish proteins that are merely co-localized in the same compartment from those that are undergoing protein-protein interactions (Kenworthy, 2001).

The earliest use of GFP in a FRET pair involved a BFP donor and an EGFP acceptor (Heim and Tsien, 1996), a combination that was later replaced by the ECFP/YFP pair due to the improved brightness and photostability of ECFP when compared to BFP (Pollok and Heim, 1999). ECFP/YFP quickly became the most commonly used FRET pair, with ECFP being currently replaced by its improved version Cerulean, which has a higher quantum yield, extinction coefficient and, most importantly, a single fluorescence lifetime (Rizzo et al., 2004). Other popular FRET pairs include the recently developed mOrange and T-Sapphire (Shaner et al., 2004), Cerulean and Dronpa (Lukyanov et al., 2005) and EYFP and mCherry (Shaner etal., 2004). Of particular interest are the recently developed monomeric optimized versions of cyan and yellow super fluorescent proteins, termed SCFP3A and SYFP2 respectively, which fold faster and more efficiently at $37^{\circ} \mathrm{C}$ and are brighter than their predecessors CFP and YFP (Kremers, Goedhart et al., 2006). Both of them constitute an obvious FRET pair, with SCFP3A as a donor and SYFP2 as an acceptor, but SYFP2 can also act as a donor for mCherry.

FRET microscopy approaches can be divided into intensity based methods and fluorescence decay kinetics based methods (Wouters et al., 2001). Intensity based FRET techniques take advantage of the fact that excitation of a donor fluorophore in FRET results in quenching of donor emission and in an increased, sensitized acceptor emission. Detection of FRET through sensitized emission of the acceptor is a complex task that requires correction of both leak-through of the donor emission and direct excitation of the acceptor (Day, 1998, Gordon et al., 1998, Nagy et al., 1998, Xia and Liu, 2001). These corrections often involve the acquisition of images from samples with the donor alone and the acceptor alone, a pitfall that can lead to errors in the estimation of the correction parameters because the quantum yields of the donor and the acceptor might vary in the different samples

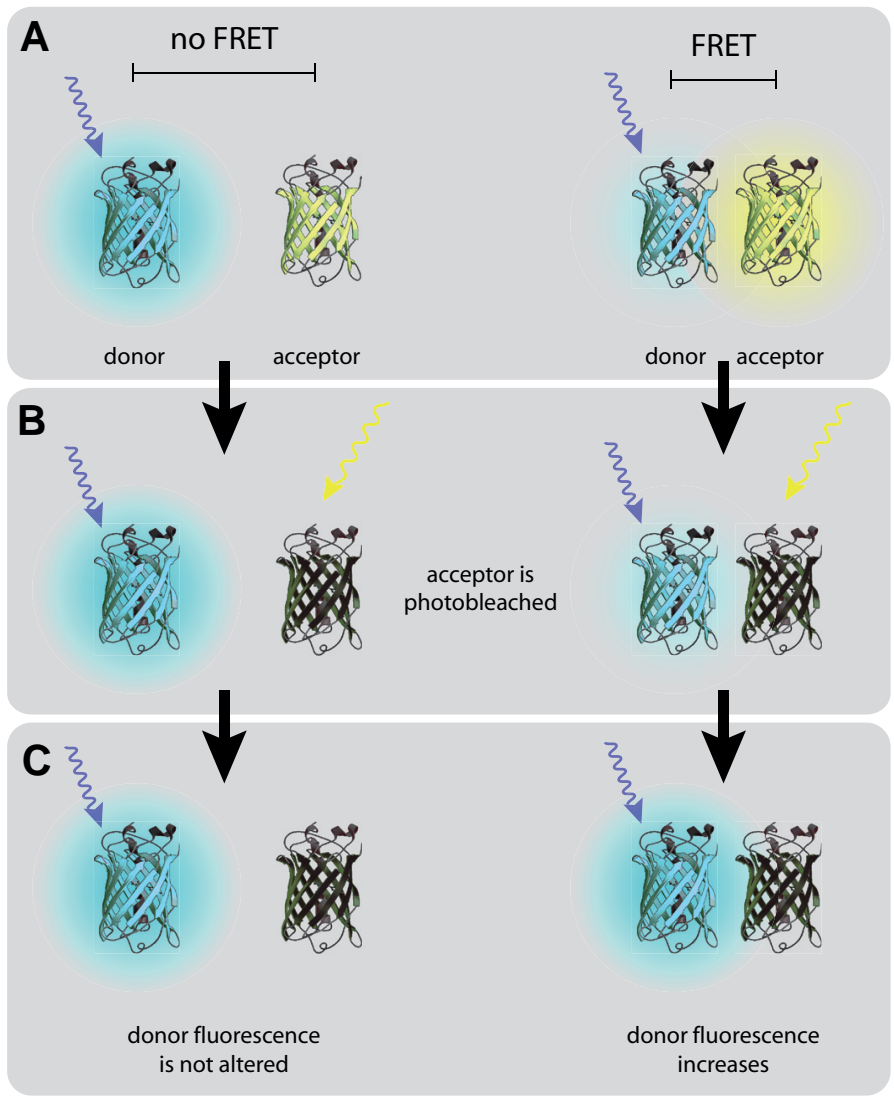

Fig. 7. Acceptor Photobleaching FRET. (A) FRET between a donor and an acceptor molecule only occurs if the distance between them is in the order of a few nanometers. FRET causes the donor fluorescence to be quenched while the acceptor undergoes sensitized emission. (B) Acceptor photobleaching FRET assesses protein-protein interactions by bleaching the acceptor molecules with a high intensity laser (yellow arrow). (C) If the donor fluorescence was being quenched by FRET, it will increase after the acceptor has been bleached.

\section{(Wouters et al., 2001).}

Another approach consists in measuring the donor fluorescence specifically, by using appropriate emission filters that eliminate the leak-through of acceptor emission (Bastiaens and Pepperkok, 2000). FRET can then be detected by comparing the quenched with the unquenched donor emission after specific photobleaching of the acceptor fluorophore (Fig. 7) (Bastiaens et al., 1996, Wouters et al., 1998). The principle behind acceptor photobleaching FRET is that energy transfer is reduced or eliminated when the acceptor is irreversibly bleached, thereby causing an increase in donor fluorescence.

Kinetic-based approaches for FRET determination measure the excited state decay kinetics of the donor or the acceptor, instead of their fluorescence intensity. The most widely used of these approaches is fluorescence lifetime imaging microscopy (FLIM) (Gadella and Jovin, 1995, Wallrabe and Periasamy, 2005, Wouters and Bastiaens, 1999), which detects the decrease in fluorescence lifetime of the donor due to the depopulation of its excited state by FRET. FLIM determines a single lifetime value for each position in an image. This measured lifetime is a nonlinear function of the true lifetimes and the populations of bound and 
unbound donor molecules in that position (Wouters et al., 2001).

Two different FLIM implementations can be distinguished. In time-domain FLIM, a short laser pulse excites the fluorophore and the subsequent emission is measured time-resolved, thus originating a decay curve which can be fitted to a lifetime value. In frequency-domain FLIM, a modulated excitation light is used to excite the fluorophore and the lifetime is determined by measuring either the phase shift or the decrease in modulation depth in the emission. Time-domain and frequency domain FLIM have been applied to both widefield (Oida et al., 1993, Squire and Bastiaens, 1999, van Munster and Gadella, 2005) and scanning microscopy (Carlsson and Liljeborg, 1997, Sanders et al., 1995).

\section{Towards super-microscopy}

More than 400 years after the advent of the compound microscope, light microscopy is still a field of intensive research and further developments will certainly provide biologists with novel tools to explore the cell. In parallel with the groundbreaking demonstration that the resolution of images obtained with a fluorescence microscope is no longer limited by the wavelength of the light, a revolution in optical components is currently emerging. Super-lenses with negative refraction indexes, a concept initially proposed by J. Pendry in 2000 (Pendry, 2000) have proven to image bellow the diffraction limit (Fang et al., 2005). Conventional lenses made of positive refraction index media limit resolution essentially because evanescent waves containing high spatial frequency information are lost. Meta-materials (reviewed in Smith et al., 2004) are artificially designed materials with unusual electromagnetic properties in which a negative refraction index is attainable. In those materials, the evanescent wave decay is compensated, thus allowing for sub-wavelength image reconstruction. A super-lens made from a thin silver slab, working at optical frequencies, was able to produce a non-magnified image with $60 \mathrm{~nm}$ resolution (Fang et al., 2005). More recently, superlenses were shown to produce magnified images with $70 \mathrm{~nm}-130$ $\mathrm{nm}$ resolution (Liu et al., 2007, Smolyaninov et al., 2007). Supermicrocopy is visibly on the horizon.

\section{Acknowledgments}

We thank Dorus Gadella for stimulating discussions and critical comments. We are also grateful to Fundação para a Ciência e Tecnologia, Portugal(POCI/SAU-MMO/57700/2004), and the European Commission (LSHG-CT-2003-503259).

\section{References}

ANDO, R., HAMA, H., YAMAMOTO-HINO, M., MIZUNO, H. and MIYAWAKI, A. (2002). An optical marker based on the UV-induced green-to-red photoconversion of a fluorescent protein. Proc Nat/ Acad Sci USA 99: 12651-6.

ANDO, R., MIZUNO, H. and MIYAWAKI, A. (2004). Regulated fast nucleocytoplasmic shuttling observed by reversible protein highlighting. Science 306: 1370-3.

ARYA, H., KAUL, Z., WADHWA, R., TAIRA, K., HIRANO, T. and KAUL, S.C. (2005). Quantum dots in bio-imaging: Revolution by the small. Biochem Biophys Res Commun 329: 1173-7.

AXELROD, D., KOPPEL, D.E., SCHLESSINGER, J., ELSON, E. and WEBB, W.W. (1976). Mobility measurement by analysis of fluorescence photobleaching recovery kinetics. Biophys J 16: 1055-69.

BACIA, K. and SCHWILLE, P. (2003). A dynamic view of cellular processes by in vivo fluorescence auto- and cross-correlation spectroscopy. Methods 29: 7485.
BASTIAENS, P.I., MAJOUL, I.V., VERVEER, P.J., SOLING, H.D. and JOVIN, T.M (1996). Imaging the intracellular trafficking and state of the AB5 quaternary structure of cholera toxin. EMBO J15: 4246-53.

BASTIAENS, P.I. and PEPPERKOK, R. (2000). Observing proteins in their natural habitat: the living cell. Trends Biochem Sci25: 631-7.

BEAUDOUIN, J., MORA-BERMUDEZ, F., KLEE, T., DAIGLE, N. and ELLENBERG, J. (2006). Dissecting the contribution of diffusion and interactions to the mobility of nuclear proteins. Biophys J90: 1878-94.

BELGAREH, N., RABUT, G., BAI, S.W., VAN OVERBEEK, M., BEAUDOUIN, J., DAIGLE, N., ZATSEPINA, O.V., PASTEAU, F., LABAS, V., FROMONT-RACINE, M. et al. (2001). An evolutionarily conserved NPC subcomplex, which redistributes in part to kinetochores in mammalian cells. J Cell Bio/154: 1147-60.

BLONK, J.C.G., DON, A., VAN AALST, H. and BIRMINGHAM, J.J. (1993). Fluorescence photobleaching recovery in the confocal scanning light microscope. Journal of Microscopy 169: 363-374.

BOISVERT, F.M., KRUHLAK, M.J., BOX, A.K., HENDZEL, M.J. and BAZETTJONES, D.P. (2001). The transcription coactivator CBP is a dynamic component of the promyelocytic leukemia nuclear body. J Cel/ Bio/152: 1099-106.

BRAECKMANS, K., PEETERS, L., SANDERS, N.N., DE SMEDT, S.C. and DEMEESTER, J. (2003). Three-dimensional fluorescence recovery after photobleaching with the confocal scanning laser microscope. Biophys $J$ 85: 2240-52.

BRAECKMANS, K., STUBBE, B.G., REMAUT, K., DEMEESTER, J. and DE SMEDT, S.C. (2006). Anomalous photobleaching in fluorescence recovery after photobleaching measurements due to excitation saturation-a case study for fluorescein. J Biomed Opt 11: 044013

BRAGA, J., DESTERRO, J.M. and CARMO-FONSECA, M. (2004). Intracellular macromolecular mobility measured by fluorescence recovery after photobleaching with confocal laser scanning microscopes. Mol Biol Cel/ 15 : 4749-60.

BRAGA, J., MCNALLY, J.G. and CARMO-FONSECA, M. (2007). A reactiondiffusion model to study RNA motion by quantitative fluorescence recovery after photobleaching. Biophys J92: 2694-703.

CAMPBELL, R.E., TOUR, O., PALMER, A.E., STEINBACH, P.A., BAIRD, G.S. ZACHARIAS, D.A. and TSIEN, R.Y. (2002). A monomeric red fluorescent protein. Proc Natl Acad Sci USA 99: 7877-82.

CARLSSON, K. and LILJEBORG, A. (1997). Confocal fluorescence microscopy using spectral and lifetime information to simultaneously record four-fluorophores with high channel separation. J. Microsc.37-46.

CARRERO, G., MCDONALD, D., CRAWFORD, E., DE VRIES, G. and HENDZEL, M.J. (2003). Using FRAP and mathematical modeling to determine the in vivo kinetics of nuclear proteins. Methods 29: 14-28.

CHAPMAN, S., OPARKA, K.J. and ROBERTS, A.G. (2005). New tools for in vivo fluorescence tagging. Curr Opin Plant Bio/8: 565-73.

CHEUTIN, T., MCNAIRN, A.J., JENUWEIN, T., GILBERT, D.M., SINGH, P.B. and MISTELI, T. (2003). Maintenance of stable heterochromatin domains by dynamic HP1 binding. Science 299: 721-5.

CHUDAKOV, D.M., BELOUSOV, V.V., ZARAISKY, A.G., NOVOSELOV, V.V., STAROVEROV, D.B., ZOROV, D.B., LUKYANOV, S. and LUKYANOV, K.A. (2003). Kindling fluorescent proteins for precise in vivo photolabeling. Nat Biotechno/21: 191-4.

CHUDAKOV, D.M., VERKHUSHA, V.V., STAROVEROV, D.B., SOUSLOVA, E.A., LUKYANOV, S. and LUKYANOV, K.A. (2004). Photoswitchable cyan fluorescent protein for protein tracking. Nat Biotechno/22: 1435-9.

CHUDAKOV, D.M., LUKYANOV, S. et al. (2007). Tracking intracellular protein movements using photoswitchable fluorescent proteins PS-CFP2 and Dendra2. Nat Protoc 2: 2024-2032.

COLE, N.B., SMITH, C.L., SCIAKY, N., TERASAKI, M., EDIDIN, M. and LIPPINCOTT-SCHWARTZ, J. (1996). Diffusional mobility of Golgi proteins in membranes of living cells. Science 273: 797-801.

CONE, R.A. (1972). Rotational diffusion of rhodopsin in the visual receptor membrane. Nat New Bio/236: 39-43.

CUBITT, A.B., HEIM, R., ADAMS, S.R., BOYD, A.E., GROSS, L.A. and TSIEN, R.Y (1995). Understanding, improving and using green fluorescent proteins. Trends Biochem Sci20: 448-55. 
DAHAN, M., LEVI, S., LUCCARDINI, C., ROSTAING, P., RIVEAU, B. and TRILLER, A. (2003). Diffusion dynamics of glycine receptors revealed by single-quantum dot tracking. Science 302: 442-5.

DAY, R.N. (1998). Visualization of Pit-1 transcription factor interactions in the living cell nucleus by fluorescence resonance energy transfer microscopy. Mo/ Endocrino/ 12: 1410-9.

DENK, W., STRICKLER, J.H. and WEBB, W.W. (1990). Two-photon laser scanning fluorescence microscopy. Science 248: 73-6.

DERYUSHEVA, S. and GALL, J.G. (2004). Dynamics of coilin in Cajal bodies of the Xenopus germinal vesicle. Proc Nat/ Acad Sci USA 101: 4810-4

DESTERRO, J.M., KEEGAN, L.P., LAFARGA, M., BERCIANO, M.T., O'CONNELL, M. and CARMO-FONSECA, M. (2003). Dynamic association of RNA-editing enzymes with the nucleolus. J Cel/ Sci116: 1805-18.

DUNDR, M., HOFFMANN-ROHRER, U., HU, Q., GRUMMT, I., ROTHBLUM, L.I., PHAIR, R.D. and MISTELI, T. (2002). A kinetic framework for a mammalian RNA polymerase in vivo. Science 298: 1623-6.

DYBA, M. and HELL, S.W. (2002). Focal spots of size lambda/23 open up far-field fluorescence microscopy at $33 \mathrm{~nm}$ axial resolution. Phys Rev Lett 88: 163901.

EDIDIN, M., ZAGYANSKY, Y. and LARDNER, T.J. (1976). Measurement of membrane protein lateral diffusion in single cells. Science 191: 466-8.

ELSON, E. and MAGDE, D. (1974). Fluorescence correlation spectroscopy. I. Conceptual basis and theory. Biopolymers 13: 1.

ELSON, E.L. (2004). Quick tour of fluorescence correlation spectroscopy from its inception. J Biomed Opt 9: 857-64.

FANG, N., LEE, H., SUN, C. and ZHANG, X. (2005). Sub-diffraction-limited optical imaging with a silver superlens. Science 308: 534-7.

GADELLA, T.W.J. and JOVIN, T.M. (1995). Oligomerization of epidermal growth factor receptors on A431 cells studied by time-resolved fluorescence imaging microscopy. A stereochemical model for tyrosine kinase receptor activation. $J$ Cell Bio/129: 1543-58.

GAO, X., YANG, L., PETROS, J.A., MARSHALL, F.F., SIMONS, J.W. and NIE, S (2005). In vivo molecular and cellular imaging with quantum dots. Curr Opin Biotechno/16: 63-72.

GOODWIN, J.S. and KENWORTHY, A.K. (2005). Photobleaching approaches to investigate diffusional mobility and trafficking of Ras in living cells. Methods 37: 154-64.

GORDON, G.W., BERRY, G., LIANG, X.H., LEVINE, B. and HERMAN, B. (1998). Quantitative fluorescence resonance energy transfer measurements using fluorescence microscopy. Biophys J74: 2702-13.

GOSCH, M. and RIGLER, R. (2005). Fluorescence correlation spectroscopy of molecular motions and kinetics. Adv Drug Deliv Rev 57: 169-90.

GURSKAYA, N.G., VERKHUSHA, V.V., SHCHEGLOV, A.S., STAROVEROV, D.B., CHEPURNYKH, T.V., FRADKOV, A.F., LUKYANOV, S. and LUKYANOV, K.A. (2006). Engineering of a monomeric green-to-red photoactivatable fluorescent protein induced by blue light. Nat Biotechno/24: 461-5.

GUSTAFSSON, M.G., AGARD, D.A. and SEDAT, J.W. (1999). I5M: 3D widefield light microscopy with better than $100 \mathrm{~nm}$ axial resolution. JMicrosc 195: 10-6.

HANDWERGER, K.E., MURPHY, C. and GALL, J.G. (2003). Steady-state dynamics of Cajal body components in the Xenopus germinal vesicle. J Cel/ Bio/160: 495-504.

HARRER, M., LUHRS, H., BUSTIN, M., SCHEER, U. and HOCK, R. (2004). Dynamic interaction of HMGA1 a proteins with chromatin. J Cel/ Sci117: 345971.

HEIM, R., CUBITT, A.B. and TSIEN, R.Y. (1995). Improved green fluorescence. Nature 373: 663-4.

HEIM, R. and TSIEN, R.Y. (1996). Engineering green fluorescent protein for improved brightness, longer wavelengths and fluorescence resonance energy transfer. Curr Bio/6: 178-82.

HELL, S.W., REINER, G., CREMER, C. and STELZER, E.H.K. (1993). Aberrations in confocal fluorescence microscopy induced by mismatches in refractive index. Journal of Microscopy 169: 391-405.

HELL, S.W. and STELZER, E.H.K. (1992a). Fundamental improvement of resolution with a 4Pi-confocal fluorescence microscope using two-photon excitation. Opt. Commun. 277-282.
HELL, S.W. and STELZER, E.H.K. (1992b). Properties of a 4Pi-confocal fluorescence microscope. J. Opt. Soc. Am. A 9: 2159-2166.

HELL, S.W. and STELZER, E.H.K. (1995). Lens Aberrations in Confocal Fluorescence Microscopy. In Handbook of Biological Confocal Microscopy, (ed. PAWLEY, J. B.). Plenum Press, New York.

HELL, S.W. and WICHMAN, J. (1994). Breaking the diffraction resolution limit by stimulated emission. Opt. Lett. 19: 780-782.

HOUTSMULLER, A.B., RADEMAKERS, S., NIGG, A.L., HOOGSTRATEN, D., HOEIJMAKERS, J.H. and VERMEULEN, W. (1999). Action of DNA repair endonuclease ERCC1/XPF in living cells. Science 284: 958-61.

HOUTSMULLER, A.B. and VERMEULEN, W. (2001). Macromolecular dynamics in living cell nuclei revealed by fluorescence redistribution after photobleaching. Histochem Cell Biol115: 13-21.

HUISKEN, J., SWOGER, J., DEL BENE, F., WITTBRODT, J. and STELZER, E.H (2004). Optical sectioning deep inside live embryos by selective plane illumination microscopy. Science 305: 1007-9.

KENWORTHY, A.K. (2001). Imaging protein-protein interactions using fluorescence resonance energy transfer microscopy. Methods 24: 289-96.

KIM, S.A., HEINZE, K.G., BACIA, K., WAXHAM, M.N. and SCHWILLE, P. (2005). Two-photon cross-correlation analysis of intracellular reactions with variable stoichiometry. Biophys J88: 4319-36.

KIMURA, H. and COOK, P.R. (2001). Kinetics of core histones in living human cells: little exchange of $\mathrm{H} 3$ and $\mathrm{H} 4$ and some rapid exchange of $\mathrm{H} 2 \mathrm{~B}$. J Ce// Bio/153: 1341-53.

KLAR, T.A., JAKOBS, S., DYBA, M., EGNER, A. and HELL, S.W. (2000). Fluorescence microscopy with diffraction resolution barrier broken by stimulated emission. Proc Nat/ Acad Sci USA 97: 8206-10.

KREMERS, G.J., GOEDHART, J. et al. (2006). Cyan and yellow super fluorescent proteins with improved brightness, protein folding, and FRET Forster radius. Biochemistry 45: 6570-80

KUBITSCHECK, U., WEDEKIND, P. and PETERS, R. (1998). Three-dimensiona diffusion measurements by scanning microphotolysis. Journal of Microscopy 192: 126-138

LAM, M.H., THOMAS, R.J., LOVELAND, K.L., SCHILDERS, S., GU, M., MARTIN, T.J., GILLESPIE, M.T. and JANS, D.A. (2002). Nuclear transport of parathyroid hormone (PTH)-related protein is dependent on microtubules. Mol Endocrinol 16: 390-401

LANG, I., SCHOLZ, M. and PETERS, R. (1986). Molecular mobility and nucleocytoplasmic flux in hepatoma cells. J Cel/ Bio/102: 1183-90.

LICHTMAN, J.W. and CONCHELLO, J.A. (2005). Fluorescence microscopy. Nat Methods 2: 910-9.

LIPPINCOTT-SCHWARTZ, J., ALTAN-BONNET, N. and PATTERSON, G.H. (2003). Photobleaching and photoactivation: following protein dynamics in living cells. Nat Cel/ Bio/Suppl: S7-14.

LIPPINCOTT-SCHWARTZ, J. and PATTERSON, G.H. (2003). Development and use of fluorescent protein markers in living cells. Science 300: 87-91.

LIPPINCOTT-SCHWARTZ, J., SNAPP, E. and KENWORTHY, A. (2001). Studying protein dynamics in living cells. Nat Rev Mol Cel/ Bio/2: 444-56.

LIU, Z., LEE, H., XIONG, Y., SUN, C. and ZHANG, X. (2007). Far-field optical hyperlens magnifying sub-diffraction-limited objects. Science 315: 1686.

LUKYANOV, K.A., CHUDAKOV, D.M., LUKYANOV, S. and VERKHUSHA, V.V. (2005). Innovation: Photoactivatable fluorescent proteins. Nat Rev Mol Cel/ Biol 6: 885-91.

MATZ, M.V., FRADKOV, A.F., LABAS, Y.A., SAVITSKY, A.P., ZARAISKY, A.G., MARKELOV, M.L. and LUKYANOV, S.A. (1999). Fluorescent proteins from nonbioluminescent Anthozoa species. Nat Biotechno/17: 969-73.

MCDONALD, D., CARRERO, G., ANDRIN, C., DE VRIES, G. and HENDZEL, M.J. (2006). Nucleoplasmic beta-actin exists in a dynamic equilibrium between lowmobility polymeric species and rapidly diffusing populations. J Cel/ Bio/ 172 541-52.

MCNALLY, J.G., MULLER, W.G., WALKER, D., WOLFORD, R. and HAGER, G.L. (2000). The glucocorticoid receptor: rapid exchange with regulatory sites in living cells. Science 287: 1262-5.

MICHALET, X., PINAUD, F.F., BENTOLILA, L.A., TSAY, J.M., DOOSE, S., LI, J.J., SUNDARESAN, G., WU, A.M., GAMBHIR, S.S. and WEISS, S. (2005). Quan- 
tum dots for live cells, in vivo imaging, and diagnostics. Science 307: 538-44.

MINSKY, M. (1988). Memoir on inventing the confocal scanning microscope. Scanning 128-138.

NAGY, P., VAMOSI, G., BODNAR, A., LOCKETT, S.J. and SZOLLOSI, J. (1998). Intensity-based energy transfer measurements in digital imaging microscopy. Eur Biophys J27: 377-89.

NAKANO, A. (2002). Spinning-disk confocal microscopy - a cutting-edge tool for imaging of membrane traffic. Cel/ Struct Funct 27: 349-55.

OIDA, T., SAKO, Y. and KUSUMI, A. (1993). Fluorescence lifetime imaging microscopy (flimscopy). Methodology development and application to studies of endosome fusion in single cells. Biophys J64: 676-85.

ORMO, M., CUBITT, A.B., KALLIO, K., GROSS, L.A., TSIEN, R.Y. and REMINGTON, S.J. (1996). Crystal structure of the Aequorea victoria green fluorescent protein. Science 273: 1392-5.

PATTERSON, G.H. and LIPPINCOTT-SCHWARTZ, J. (2002). A photoactivatable GFP for selective photolabeling of proteins and cells. Science 297: 1873-7.

PENDRY, J.B. (2000). Negative refraction makes a perfect lens. Phys Rev Lett85: 3966-9.

PETERS, R., PETERS, J., TEWS, K.H. and BAHR, W. (1974). A microfluorimetric study of translational diffusion in erythrocyte membranes. Biochim Biophys Acta 367: 282-94.

POLLOK, B.A. and HEIM, R. (1999). Using GFP in FRET-based applications. Trends Cell Bio/9: 57-60.

POO, M. and CONE, R.A. (1973). Lateral diffusion of rhodopsin in the visual receptor membrane. J Supramo/ Struct 1: 354.

PRENDERGAST, F.G. (1999). Biophysics of the Green Fluorescent Protein. In Green Fluorescent Proteins, vol. 58 (ed. SULLIVAN, K. F. and KAY, S. A.). Academic Press, New York.

RABUT, G., LENART, P. and ELLENBERG, J. (2004). Dynamics of nuclear pore complex organization through the cell cycle. Curr Opin Cell Bio/16: 314-21.

RADEMAKERS, S., VOLKER, M., HOOGSTRATEN, D., NIGG, A.L., MONE, M.J., VAN ZEELAND, A.A., HOEIJMAKERS, J.H., HOUTSMULLER, A.B. and VERMEULEN, W. (2003). Xeroderma pigmentosum group A protein loads as a separate factor onto DNA lesions. Mol Cel/ Bio/23: 5755-67.

REID, B.G. and FLYNN, G.C. (1997). Chromophore formation in green fluorescent protein. Biochemistry 36: 6786-91.

RIZZO, M.A., SPRINGER, G.H., GRANADA, B. and PISTON, D.W. (2004). An improved cyan fluorescent protein variant useful for FRET. Nat Biotechno/22: 445-9.

SANDERS, R., DRAAIJER, A., GERRITSEN, H.C., HOUPT, P.M. and LEVINE, Y.K. (1995). Quantitative pH imaging in cells using confocal fluorescence lifetime imaging microscopy. Anal Biochem 227: 302-8.

SCHWILLE, P. (2001). Fluorescence correlation spectroscopy and its potential for intracellular applications. Cell Biochem Biophys 34: 383-408.

SCHWILLE, P., HAUPTS, U., MAITI, S. and WEBB, W.W. (1999). Molecular dynamics in living cells observed by fluorescence correlation spectroscopy with one- and two-photon excitation. Biophys J77: 2251-65.

SELVIN, P.R. (2000). The renaissance of fluorescence resonance energy transfer. Nat Struct Bio/7: 730-4.

SHANER, N.C., CAMPBELL, R.E., STEINBACH, P.A., GIEPMANS, B.N., PALMER, A.E. and TSIEN, R.Y. (2004). Improved monomeric red, orange and yellow fluorescent proteins derived from Discosoma sp. red fluorescent protein. Nat Biotechno/22: 1567-72.

SHANER, N.C., STEINBACH, P.A. and TSIEN, R.Y. (2005). A guide to choosing fluorescent proteins. Nat Methods 2: 905-9.

SMITH, D.R., PENDRY, J.B. and WILTSHIRE, M.C. (2004). Metamaterials and negative refractive index. Science 305: 788-92.

SMOLYANINOV, II, HUNG, Y.J. and DAVIS, C.C. (2007). Magnifying superlens in the visible frequency range. Science 315: 1699-701.

SPRAGUE, B.L., MULLER, F., PEGO, R.L., BUNGAY, P.M., STAVREVA, D.A. and MCNALLY, J.G. (2006). Analysis of binding at a single spatially localized cluster of binding sites by fluorescence recovery after photobleaching. Biophys J91:
1169-91.

SPRAGUE, B.L., PEGO, R.L., STAVREVA, D.A. and MCNALLY, J.G. (2004). Analysis of binding reactions by fluorescence recovery after photobleaching. Biophys J86: 3473-95.

SQUIRE, A. and BASTIAENS, P.I. (1999). Three dimensional image restoration in fluorescence lifetime imaging microscopy. J Microsc 193: 36-49.

STELZER, E.H.K. (1995). The Intermediate Optical System of Laser-Scanning Confocal Microscopes. In Handbook of Biological Confocal Microscopy, (ed. PAWLEY, J. B.). Plenum Press, New York.

STIEL, A.C., TROWITZSCH, S. et al. (2007). 1.8 A bright-state structure of the reversibly switchable fluorescent protein Dronpa guides the generation of fast switching variants. Biochem J402: 35-42.

STOKES, G.G. (1852). On the change of refrangibility of light. Phil. Trans. R. Soc. London 463-562.

SUNN, K.L., EISMAN, J.A., GARDINER, E.M. and JANS, D.A. (2005). FRAP analysis of nucleocytoplasmic dynamics of the vitamin $D$ receptor splice variant VDRB1: preferential targeting to nuclear speckles. Biochem J388: 509-14.

TAVANEZ, J.P., CALADO, P., BRAGA, J., LAFARGA, M. and CARMO-FONSECA, $M$. (2005). In vivo aggregation properties of the nuclear poly(A)-binding protein PABPN1. RNA 11: 752-62.

TRINKLE-MULCAHY, L., SLEEMAN, J.E. and LAMOND, A.I. (2001). Dynamic targeting of protein phosphatase 1 within the nuclei of living mammalian cells. $J$ Cell Sci114: 4219-28.

TRUONG, K. and IKURA, M. (2001). The use of FRET imaging microscopy to detect protein-protein interactions and protein conformational changes in vivo. Curr Opin Struct Bio/11: 573-8.

TSIEN, R.Y. (1998). The green fluorescent protein. Annu Rev Biochem67: 509-44. TSIEN, R.Y. (2005). Building and breeding molecules to spy on cells and tumors. FEBS Lett 579: 927-32.

VAN MUNSTER, E.B. and GADELLA, T.W. (2005). Fluorescence lifetime imaging microscopy (FLIM). Adv Biochem Eng Biotechno/95: 143-75.

VERKHUSHA, V.V. and SORKIN, A. (2005). Conversion of the monomeric red fluorescent protein into a photoactivatable probe. Chem Biol12: 279-85.

VERVEER, P.J., SWOGER, J., PAMPALONI, F., GREGER, K., MARCELLO, M. and STELZER, E.H. (2007). High-resolution three-dimensional imaging of large specimens with light sheet-based microscopy. Nat Methods 4: 311-3.

VOSS, T.C., DEMARCO, I.A. and DAY, R.N. (2005). Quantitative imaging of protein interactions in the cell nucleus. Biotechniques 38: 413-24.

WALLRABE, H. and PERIASAMY, A. (2005). Imaging protein molecules using FRET and FLIM microscopy. Curr Opin Biotechno/16: 19-27.

WANG, E., BABBEY, C.M. and DUNN, K.W. (2005). Performance comparison between the high-speed Yokogawa spinning disc confocal system and singlepoint scanning confocal systems. J Microsc 218: 148-59.

WILLIG, K.I., RIZZOLI, S.O., WESTPHAL, V., JAHN, R. and HELL, S.W. (2006). STED microscopy reveals that synaptotagmin remains clustered after synaptic vesicle exocytosis. Nature 440: 935-9.

WOUTERS, F.S. and BASTIAENS, P.I. (1999). Fluorescence lifetime imaging of receptor tyrosine kinase activity in cells. Curr Bio/9: 1127-30.

WOUTERS, F.S., BASTIAENS, P.I., WIRTZ, K.W. and JOVIN, T.M. (1998). FRET microscopy demonstrates molecular association of non-specific lipid transfer protein (nsL-TP) with fatty acid oxidation enzymes in peroxisomes. EMBO J17: 7179-89.

WOUTERS, F.S., VERVEER, P.J. and BASTIAENS, P.I. (2001). Imaging biochemistry inside cells. Trends Cell Bio/11: 203-11.

XIA, Z. and LIU, Y. (2001). Reliable and global measurement of fluorescence resonance energy transfer using fluorescence microscopes. Biophys $J 81$ : 2395-402.

ZAPATA-HOMMER, O. and GRIESBECK, O. (2003). Efficiently folding and circularly permuted variants of the Sapphire mutant of GFP. BMC Biotechno/3: 5 .

ZHANG, J., CAMPBELL, R.E., TING, A.Y. and TSIEN, R.Y. (2002). Creating new fluorescent probes for cell biology. Nat Rev Mol Cell Bio/3: 906-18. 


\section{Further Related Reading, published previously in the Int. J. Dev. Biol.}

See our Special Issue Ear Development edited by Fernando Giraldez and Bernd Fritzsch at: http://www.ijdb.ehu.es/web/contents.php?vol=51\&issue=6-7

See our recent Special Issue Fertilization, in honor of David L. Garbers and edited by Paul M. Wassarman and Victor D. Vacquier at: http://www.ijdb.ehu.es/web/contents.php?vol=52\&issue=5-6

Visualization of primordial germ cells in vivo using GFP-nos1 3'UTR mRNA

Taiju Saito, Takafumi Fujimoto, Shingo Maegawa, Kunio Inoue, Minoru Tanaka, Katsutoshi Arai and Etsuro Yamaha

Int. J. Dev. Biol. (2006) 50: 691-700

Transient expression of apoaequorin in zebrafish embryos: extending the ability to image calcium transients during later stages of development

Chris Y. Cheung, Sarah E. Webb, Anming Meng and Andrew L. Miller

Int. J. Dev. Biol. (2006) 50: 561-569

Involvement of Hex in the initiation of feather morphogenesis

Akiko Obinata and Yoshihiro Akimoto

Int. J. Dev. Biol. (2005) 49: 953-960

The formation of primordial germ cells from germline cells in spherical embryos derived from the blastodisc of 2-cell embryos in goldfish, Carassius auratus

Satoshi Otani, Tomoe Kitauchi, Taiju Saito, Suzu Sakao, Shingo Maegawa, Kunio Inoue, Katsutoshi Arai and Etsuro Yamaha

Int. J. Dev. Biol. (2005) 49: 843-850

Expression and activity of osteoblast-targeted Cre recombinase transgenes in murine skeletal tissues

Fei Liu, Henning W. Woitge, Alen Braut, Mark S. Kronenberg, Alexander C. Lichtler, Mina Mina and Barbara E. Kream

Int. J. Dev. Biol. (2004) 48: 645-653

X-chromosome inactivation in differentiating mouse embryonic stem cells carrying $\mathrm{X}$ linked GFP and lacZ transgenes

Shirin Farivar, Shinpei Yamaguchi, Michihiko Sugimoto and Nobuo Takagi

Int. J. Dev. Biol. (2004) 48: 629-635

A P19CI6 GFP reporter line to quantify cardiomyocyte differentiation of stem cells. Jennifer C Moore, Rene Spijker, Anton C Martens, Teun de Boer, Martin B Rook, Marcel A G van der Heyden, Leon G Tertoolen and Christine L Mummery

Int. J. Dev. Biol. (2004) 48: 47-55

Analysis of the odontogenic and osteogenic potentials of dental pulp in vivo using a Col1a1-2.3-GFP transgene.

Alen Braut, Edward J Kollar and Mina Mina

Int. J. Dev. Biol. (2003) 47: 281-292

A screen for genes expressed in Drosophila imaginal discs. Offer Gerlitz, Denise Nellen, Michael Ottiger and Konrad Basler Int. J. Dev. Biol. (2002) 46: 173-176

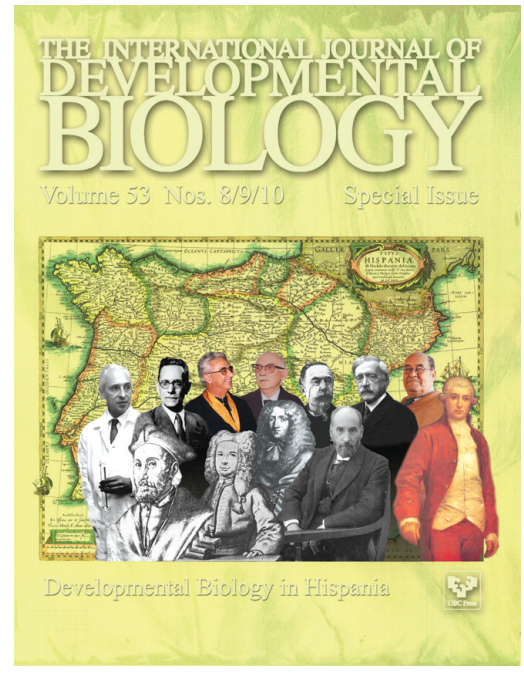

5 yr ISI Impact Factor $(2008)=3.271$

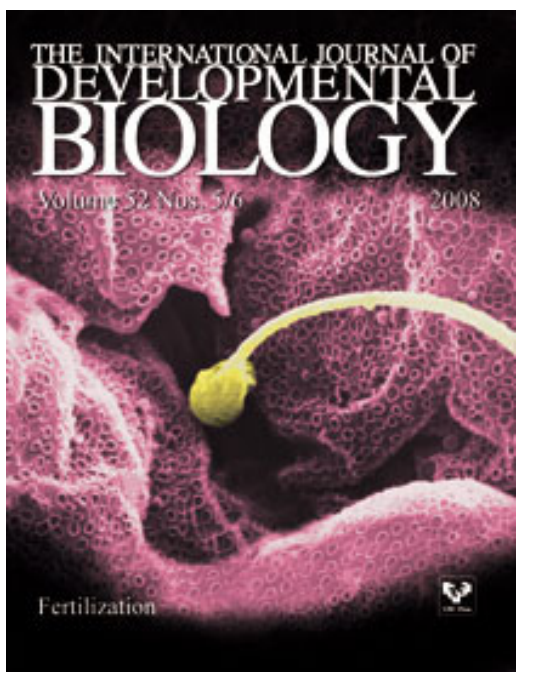

